\title{
Factors associated with bullying victimization among Korean adolescents
}

\author{
This article was published in the following Dove Press journal: \\ Neuropsychiatric Disease and Treatment \\ 18 September 2017 \\ Number of times this article has been viewed
}

\author{
Hye-jin Seo' \\ Young-Eun Jung ${ }^{2}$ \\ Moon-Doo Kim² \\ Won-Myong Bahk ${ }^{3}$ \\ 'Department of Psychiatry, Ansan \\ Shinwoo Hospital, Ansan, ${ }^{2}$ Department \\ of Psychiatry, School of Medicine, Jeju \\ National University, Jeju, ${ }^{3}$ Department \\ of Psychiatry, College of Medicine, The \\ Catholic University of Korea, Seoul, \\ Republic of Korea
}

Objectives: The aims of the present study were to assess the prevalence of bullying victimization among Korean adolescents by sex and age and to investigate the correlates of this phenomenon.

Methods: Of 3,200 eligible subjects, 2,936 (91.8\%) adolescents were recruited from four elementary schools (6th grade, age range: 10-12 years), five middle schools (8th grade, age range: 13-14 years), and three high schools (10th grade, age range: $15-17$ years) located in the Jeju Special Self-Governing Province, Republic of Korea. This study used a self-administered questionnaire to collect data on sociodemographic characteristics and experiences of bullying victimization and employed the Korean form of the Children's Depression Inventory to evaluate depressive symptoms.

Results: Of the total sample of 2,936 students, 1,689 were boys (57.5\%) and 1,247 were girls (42.5\%). The prevalence of bullying victimization by age group was as follows: 10-12 years, $9.5 \%$; $13-14$ years, $8.3 \%$; and $15-17$ years, $6.4 \%$. A significant difference in the prevalence of bullying victimization was observed by sex (boys: $45.0 \%$, girls: $55.0 \%$ ). Overall, the prevalence decreased with age. After adjusting for age and sex, bullying victimization was significantly associated with lower socioeconomic status (odds ratio $[\mathrm{OR}]=1.67 ; 95 \%$ confidence interval [CI] 1.04-2.67), lower than average academic achievement (OR $=1.77$; 95\% CI 1.25-2.50), more depressive symptoms ( $\mathrm{OR}=1.88 ; 95 \% \mathrm{CI} 1.38-2.55)$, and poorer perceived relationship with parents $(\mathrm{OR}=1.46 ; 95 \% \mathrm{CI} 1.00-2.14)$.

Conclusion: Our findings will provide researchers and public health practitioners with data on the prevalence of bullying victimization and help to identify the risk factors for later behavioral and emotional problems.

Keywords: bullying, adolescent, risk factors, Korea, students

\section{Introduction}

Bullying is defined as any repeated negative activity or aggression intended to harm or bother someone who is perceived by peers as being physically or psychologically less powerful than the aggressors. ${ }^{1}$ Bullying behavior can be physical (hitting, pushing, and kicking), verbal (name calling, provoking, making threats, and spreading rumors), or include other behaviors, such as making faces or social exclusion. ${ }^{2}$

School bullying is the most common type of school violence and is a major source of victimization among children and adolescents. ${ }^{3,4}$ It is associated with more serious violent behaviors and can have consequences for multiple health behaviors and health outcomes. ${ }^{5,6}$ In South Korea, increased social attention has been focused on bullying following a case of homicide and suicide in which bullying was a precipitating factor. ${ }^{7}$

Victimization due to school bullying is associated with behavioral, emotional, and social problems. It also appears that bullying can lead to serious mental and physical
Correspondence: Moon-Doo Kim Department of Psychiatry, School of Medicine, Jeju National University, I5 Aran 13-gil, Jeju 690-767, Republic of Korea

Tel +82 $64717 \quad 1234$

Fax +82 647171849

Email mdkim66@jejunu.ac.kr 
sequelae for victims. ${ }^{3}$ Victimized children have a higher probability of developing clinical problems, such as bed wetting, sleep difficulties, anxiety, depression, school phobia, feelings of insecurity, and unhappiness at school. They can also suffer from low self-esteem, loneliness, isolation, and somatic symptoms. ${ }^{5}$ Longitudinal investigations have shown that exposure to bullying during childhood can result in difficulties with peer relationships and severe depression later in adult life. ${ }^{8-10}$ Meltzer et al reported that adults who experienced bullying in childhood are more than twice as likely as other adults to attempt suicide later in life. ${ }^{11}$

It is important that children at increased risk of victimization are identified early to facilitate timely prevention of bullying victimization. The ability to identify such children is enhanced by knowledge of the determinants and predictors of bullying behavior.

Patterns of bullying victimization may differ by sex and age, and these differences may reflect sex- and age-related developmental processes. ${ }^{12}$ The probability of being victimized differs across the developmental stages of childhood. ${ }^{13}$ It is necessary to understand the differences in the patterns of peer victimization associated with specific developmental stages to develop appropriate interventions.

Although several studies have been conducted in other countries, it is difficult to generalize these results to Korea. South Korean society may have the hyper-competitive nature. Korean students are being pushed into an environment of competition to succeed. They do not see their peers as friends but as competition. For these reasons, the prevalence and correlates of victimization among Korean adolescents may be different from other countries.

As far as we know, few studies have been performed on a wide age range of Korean adolescents. Indeed, most studies of bullying victimization in Korea have focused only on specific ages or specific school grades (middle school or high school)..$^{3,5,14,15}$ Therefore, the aim of the present study was to assess the prevalence of peer victimization by sex and age and to identify its correlates among adolescents in elementary, middle, and high schools on Jeju Island, Korea.

\section{Methods}

\section{Participants}

Of 3,200 eligible subjects, 2,936 (91.8\%) adolescents were recruited from four elementary schools (6th grade, age range: $10-12$ years), five middle schools (8th grade, age range: $13-14$ years), and three high schools (11th grade, age range: 15-17 years) located in the Jeju Special Self-Governing Province, Republic of Korea. This study was designed to assess the prevalence of bullying victimization in adolescents aged 10-17 years and examine its association with sex and age group (10-12, 13-14, and 15-17 years). We choose 6th, 8th, and 11 th graders to represent each age group. The four regions of Jeju-si, Seogwipo-si, South Jeju, and North Jeju represent the four districts on Jeju Island. The number of schools chosen from each region was determined according to the proportion of the student population and the number of schools in the region: one elementary school from each region, two middle schools from Seogwipo-si, one middle school from each of North Jeju and South Jeju, one high school from each of Jeju-si and North Jeju, and one shared high school from Seogwipo-si and South Jeju. The target schools volunteered to participate in the study and were selected to represent typical Korean public schools. After gaining written approval, researchers visited the schools, explained the purpose of the study to the students and teachers, and received written informed consent from students over 16 years old and teachers. The researchers also sent the parents letters explaining the purpose of the study. The parents provided written informed consent for their children under the age of 16 years old to participate in this study. The letters included a statement explaining that parents and children could freely refuse to respond if they did not agree with the purpose of the study. This study was approved by the Institutional Review Board of Jeju National University Hospital.

\section{Assessment}

\section{Sociodemographic characteristics}

This study used a self-administered questionnaire to gather data on subjects' home and school lives. The study participants completed a questionnaire regarding age, sex, school grade, parental educational level, siblings, academic achievement, socioeconimic status (SES), body satisfaction, self-reported health status, and perceived relationship with parents. The questions were as follows: 1) "How would you rate your level of academic achievement?" The response categories were above average, average, and below average. 2) "What is your household's economic status?" The response categories were high, middle, and low. 3) "How would you rate your health status compared with that of your friends?" The response categories were good, fair, and poor. 4) "Are you satisfied with your body image?" The response categories were satisfied, neutral, and unsatisfied. 5) "What do you think of your relationship with your parents?" The response categories were good and poor.

\section{Bullying victimization}

A self-administered questionnaire about self-perceptions of bullying victimization was used. Questions about bullying 
victimization were preceded by the following explanation: "We say a student is being bullied when someone is intentionally and repeatedly harming or teasing that student." Bullying victimization was determined based on two questions asked of all participants: 1) "Have you ever been bullied by another student?" and 2) "Have you suffered threats or physical or verbal assault by other students?" Responses were limited to "yes" or "no." We coded subjects who answered yes to either of these questions as reporting bullying victimization.

\section{Depressive symptoms}

The Children's Depression Inventory (CDI) was used to measure depressive symptoms. ${ }^{16}$ The CDI, which consists of 27 items that assess subjective severity and various symptoms of depression, is suitable for children between the ages of 7 and 17 years. Total scores range from 0 to 54, with higher scores indicating more severe depression. We used the Korean form of the CDI, and the presence of depressive symptoms was indicated by a score of $\geq 17$, according to a previous validation study in Korea. ${ }^{17}$ The reliability and validity of the Korean form of the CDI have been found to be acceptable (Cronbach's $\alpha=0.88$ ).

\section{Statistical analysis}

Our analysis used the chi-square test for categorical variables and the independent $t$-test for continuous variables. For the correlates analyses, univariate associations between independent variables and bullying victimization were investigated. Factors potentially associated with bullying victimization on univariate analyses were then entered simultaneously into a logistic regression model to assess independence, after adjusting for age and sex. Odds ratio (OR) and corresponding 95\% confidence intervals (CIs) were calculated. Two-tailed $p$-values with an alpha level of 0.05 were considered significant. All statistical analyses were conducted using IBM SPSS Statistics for Windows (version 20.0; IBM Corporation, Armonk, NY, USA).

\section{Results}

The total sample of 2,936 students included 1,689 boys $(57.5 \%)$ and 1,247 girls $(42.5 \%)$. The mean ( \pm standard deviation) age was $13.8 \pm 1.4$ years. There were 618 elementary school students (6th grade), 1,398 middle school students (8th grade), and 659 high school students (11th grade). We summarized the characteristics of the subjects by sex in Table 1 . Significantly more girls $(n=132,10.6 \%)$ than boys $(\mathrm{n}=108,6.4 \%)(p<0.001)$ were victimized by bullying, and girls were more likely to report body dissatisfaction than boys.
Table I Characteristics of the subjects by sex

\begin{tabular}{|c|c|c|c|c|}
\hline \multirow[t]{2}{*}{ Characteristics } & \multirow{2}{*}{$\frac{\text { Boys }}{(N=I, 689)}$} & \multirow{2}{*}{$\begin{array}{l}\text { Girls } \\
(N=I, 247)\end{array}$} & \multirow{2}{*}{$\begin{array}{l}\text { Total } \\
(\mathrm{N}=2,936)\end{array}$} & \multirow[t]{2}{*}{$p$-value } \\
\hline & & & & \\
\hline Age, mean $\pm S D$ & $13.8 \pm 1.4$ & $13.8 \pm 1.5$ & $13.8 \pm 1.4$ & 0.726 \\
\hline \multicolumn{4}{|c|}{ Age, years } & 0.005 \\
\hline $10-12$ & $362(21.6 \%)$ & 321 (25.9\%) & $683(23.5 \%)$ & \\
\hline $13-14$ & 917 (54.8\%) & $607(49.0 \%)$ & $\mathrm{I}, 524(52.4 \%)$ & \\
\hline $15-17$ & $394(23.6 \%)$ & $310(25.0 \%)$ & 704 (24.2\%) & \\
\hline \multicolumn{4}{|c|}{ Experience of bullying victimization } & $<0.001$ \\
\hline No & $1,58 \mid(93.6 \%)$ & I, I I 4 (89.4\%) & 2,695 (9l.8\%) & \\
\hline Yes & 108 (6.4\%) & $132(10.6 \%)$ & $240(8.2 \%)$ & \\
\hline \multicolumn{4}{|c|}{ Paternal education } & 1.000 \\
\hline$>12$ years & $842(66.3 \%)$ & $627(66.3 \%)$ & $1,469(66.3 \%)$ & \\
\hline$\leq 12$ years & $428(33.7 \%)$ & $318(33.7 \%)$ & $746(33.7 \%)$ & \\
\hline \multicolumn{4}{|l|}{ Maternal education } & 1.000 \\
\hline$>12$ years & $742(55.2 \%)$ & $572(55.2 \%)$ & $\mathrm{I}, 3 \mathrm{I} 4(55.2 \%)$ & \\
\hline$\leq 12$ years & $603(44.8 \%)$ & $464(44.8 \%)$ & I,067 (44.8\%) & \\
\hline \multicolumn{4}{|l|}{ Sibling } & 0.230 \\
\hline Yes & I,584 (93.8\%) & I, I 82 (94.9\%) & $2,766(94.2 \%)$ & \\
\hline No & $105(6.2 \%)$ & $64(5.1 \%)$ & $169(5.8 \%)$ & \\
\hline \multicolumn{4}{|c|}{ Socioeconomic status } & 0.078 \\
\hline High & $453(27.4 \%)$ & $287(23.3 \%)$ & $740(25.7 \%)$ & \\
\hline Middle & I,04I (63.I\%) & $830(67.5 \%)$ & I,87I (64.9\%) & \\
\hline Low & 157 (9.5\%) & $113(9.2 \%)$ & 270 (9.4\%) & \\
\hline \multicolumn{4}{|c|}{ Academic achievement } & 0.163 \\
\hline Average & $572(34 \%)$ & $432(34.9 \%)$ & 1,004 (34.4\%) & \\
\hline Above av & $418(24.9 \%)$ & 277 (22.4\%) & $695(23.8 \%)$ & \\
\hline Below average & $692(41.1 \%)$ & $530(42.8 \%)$ & $\mathrm{I}, 222(4 \mathrm{I} .8 \%)$ & \\
\hline \multicolumn{4}{|c|}{ Depressive symptoms } & 0.687 \\
\hline No & $1,168(6$ & $852(68.4 \%)$ & $2,020(68.8 \%)$ & \\
\hline Yes & $521(30.8 \%)$ & $393(31.6 \%)$ & 914 (3I.2\%) & \\
\hline \multicolumn{4}{|c|}{ Body image satisfaction } & $<0.001$ \\
\hline High & $433(25.9 \%)$ & $156(12.6 \%)$ & $589(20.2 \%)$ & \\
\hline Average & $726(61.3 \%)$ & $458(37.0 \%)$ & $\mathrm{I}, \mathrm{I} 84(40.6 \%)$ & \\
\hline Low & $516(30.8 \%)$ & 625 (50.4\%) & $\mathrm{I}, \mathrm{I} 4 \mathrm{I}$ (39.2\%) & \\
\hline \multicolumn{4}{|c|}{ Perceived health status } & 0.300 \\
\hline Good & $959(57.1 \%)$ & $70 \mathrm{I}(56.4 \%)$ & I,660 (56.8\%) & \\
\hline Fair & $565(33.6 \%)$ & 406 (32.6\%) & 971 (33.2\%) & \\
\hline Poor & $156(9.3 \%)$ & $137(11.0 \%)$ & $293(10.0 \%)$ & \\
\hline \multicolumn{4}{|c|}{ Perceived poor relationship with parents } & 0.135 \\
\hline No & $1,524(90.7 \%)$ & I, 107 (89.0\%) & $2,631(90.0 \%)$ & \\
\hline Yes & $156(9.3 \%)$ & $137(\mid 1.1 \%)$ & $293(10.0 \%)$ & \\
\hline
\end{tabular}

Note: With statistical processing, some figures were omitted when there was no data.

No differences in other sociodemographic variables were observed by sex. Most of the adolescents lived with both parents $(86.8 \%)$ and reported a middle-class SES (64.9\%). In total, $66 \%$ of fathers and $55 \%$ of mothers were college graduates. In terms of academic achievement, $41.8 \%$ of adolescents were below average and $34.4 \%$ were average. Depressive symptoms were found in $31.2 \%$ of adolescents. In total, $10 \%$ of adolescents perceived their health status and relationship with their parents to be poor.

The prevalence of bullying victimization by age group, shown in Figure 1, was as follows: 10-12 years, 9.5\%; 13-14 years, $8.3 \%$; and 15-17 years, 6.4\%. Overall, prevalence 


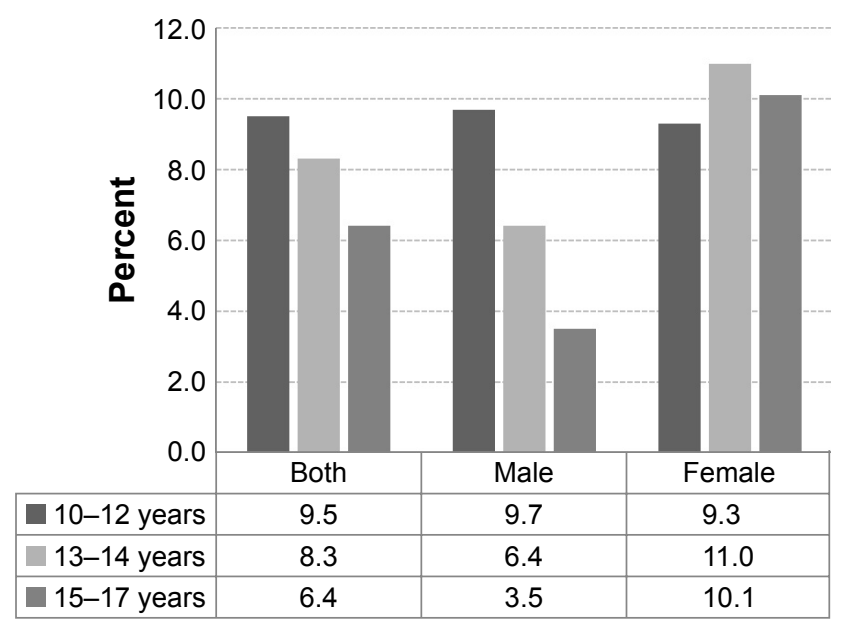

Figure I Prevalence of bullying victimization by sex and age group.

decreased with age. These patterns were similar in the analysis including only males. In females, however, the prevalence was highest in the group aged 13-14 years. The lowest prevalence $(3.5 \%)$ was found in male high school students, and the highest prevalence (11.0\%) was observed in female middle school students.

The univariate analyses revealed significant differences in the prevalence of bullying victimization by SES, academic achievement, depressive symptoms, body image satisfaction, perceived health status, and perceived relationship with parents (Table 2).

Table 3 displays the multivariate associations between independent factors and bullying victimization. After adjusting for age and sex, bullying victimization was significantly associated with lower SES (OR $=1.67,95 \%$ CI 1.04-2.67), lower than average academic achievement (OR $=1.77,95 \%$ CI 1.25-2.50), more depressive symptoms ( $\mathrm{OR}=1.88,95 \%$ CI 1.38-2.55), and poorer perceived relationship with parents ( $\mathrm{OR}=1.46,95 \%$ CI 1.00-2.14).

\section{Discussion}

In the present study, bullying victimization was found in $8.2 \%$ of adolescents: $9.5 \%$ of elementary school students, $8.3 \%$ of middle school students, and $6.4 \%$ of high school students. Consistent with previous Western studies, the percentage of children who reported being victimized by bullying ranged from $5 \%$ to $20 \%$, with an average across countries of $11 \% .{ }^{18}$ A previous study on primary school students in Korea reported a $12.5 \%$ prevalence of bullying victimization. ${ }^{14}$ However, another study of Korean students found that the prevalence rate of bullying victimization was $63.4 \% .{ }^{15}$ According to several studies of primary and secondary school children in various countries, the
Table 2 Comparisons of characteristics between subjects with and without bullying victimization

\begin{tabular}{|c|c|c|c|}
\hline \multirow[t]{2}{*}{ Characteristics } & \multicolumn{2}{|c|}{ Bullying victimization } & \multirow[t]{2}{*}{$p$-value } \\
\hline & Yes $(n=240)$ & No $(n=2,696)$ & \\
\hline Age, mean $\pm S D$ & $13.7 \pm \mid .4$ & $13.9 \pm 1.4$ & 0.041 \\
\hline \multicolumn{4}{|l|}{ Age, years } \\
\hline $10-12$ & $65(27.5 \%)$ & $618(23.1 \%)$ & 0.098 \\
\hline $13-14$ & $126(53.4 \%)$ & I,398 (52.3\%) & \\
\hline $15-17$ & $45(19.1 \%)$ & $659(24.6 \%)$ & \\
\hline \multicolumn{3}{|l|}{ Sex } & $<0.001$ \\
\hline Boys & $108(45.0 \%)$ & I,58I (58.7\%) & \\
\hline Girls & $132(55.0 \%)$ & I, I I 4 (4I.3\%) & \\
\hline \multicolumn{3}{|l|}{ Paternal education } & 0.216 \\
\hline$>12$ years & III (62.0\%) & I,358 (66.7\%) & \\
\hline$\leq 12$ years & $68(38.0 \%)$ & $678(33.3 \%)$ & \\
\hline \multicolumn{3}{|l|}{ Maternal education } & 0.291 \\
\hline$>12$ years & $93(47.7 \%)$ & $\mathrm{I}, 22 \mathrm{I}(55.9 \%)$ & \\
\hline$\leq 12$ years & $102(52.3 \%)$ & $965(44.1 \%)$ & \\
\hline \multicolumn{3}{|l|}{ Sibling } & 0.083 \\
\hline Yes & $20(8.3 \%)$ & $150(5.6 \%)$ & \\
\hline No & $220(91.7 \%)$ & $2,546(94.4 \%)$ & \\
\hline \multicolumn{3}{|c|}{ Socioeconomic status } & $<0.001$ \\
\hline High & $57(24.2 \%)$ & $683(25.8 \%)$ & \\
\hline Middle & $134(56.8 \%)$ & I,737 (65.7\%) & \\
\hline Low & 45 (19.1\%) & $225(8.5 \%)$ & \\
\hline \multicolumn{3}{|c|}{ Academic achievement } & $<0.001$ \\
\hline Average & $64 \mathrm{I}(23.9 \%)$ & $54(22.6 \%)$ & \\
\hline Above average & $950(35.4 \%)$ & $54(22.6 \%)$ & \\
\hline Below average & $\mathrm{I}, 092(40.7 \%)$ & $13 \mid(54.8 \%)$ & \\
\hline \multicolumn{3}{|c|}{ Depressive symptoms } & $<0.001$ \\
\hline No & $117(48.8 \%)$ & I,903 (70.6\%) & \\
\hline Yes & $123(51.2 \%)$ & $791(29.4 \%)$ & \\
\hline \multicolumn{3}{|c|}{ Body image satisfaction } & 0.006 \\
\hline High & $547(20.5 \%)$ & $42(17.5 \%)$ & \\
\hline Average & $\mathrm{I}, 103(4 \mathrm{I} .2 \%)$ & 81 (33.8\%) & \\
\hline Low & $\mathrm{I}, 024$ (38.3\%) & $117(48.8 \%)$ & \\
\hline \multicolumn{3}{|c|}{ Perceived health status } & 0.001 \\
\hline Good & $119(49.6 \%)$ & I,54I (57.4\%) & \\
\hline Fair & $81(33.8 \%)$ & 891 (33.2\%) & \\
\hline Poor & $40(16.7 \%)$ & $253(9.4 \%)$ & \\
\hline \multicolumn{3}{|c|}{ Perceived poor relationship with parents } & $<0.001$ \\
\hline No & $191(80.3 \%)$ & $2,400(89.9 \%)$ & \\
\hline Yes & 47 (19.7\%) & $27 \mid(10.1 \%)$ & \\
\hline
\end{tabular}

prevalence of victimization ranged from $8 \%$ to $50 \% .^{14}$ The discrepancy with the current findings might be attributable to variations across countries in instruments, definitions of victimization, sample size, and school systems. ${ }^{14}$

Significant differences were observed in the prevalence of bullying victimization by sex (boys: $45.0 \%$, girls: $55.0 \%$ ). Overall, prevalence decreased with age. The lowest prevalence (3.5\%) was found in male high school students, and the highest prevalence $(11.0 \%)$ was observed in female middle school students. All types of bullying victimization generally decline with increasing age. ${ }^{12}$ Smith et a $1^{19}$ explained this age-related decline from a developmental perspective, 
Table 3 Factors associated with bullying victimization

\begin{tabular}{|c|c|c|c|}
\hline Factors & OR & $95 \% \mathrm{Cl}$ & $p$-value \\
\hline Sex & 1.78 & $1.34-2.36$ & $<0.001$ \\
\hline Age & 0.87 & $0.78-0.96$ & 0.008 \\
\hline \multicolumn{4}{|c|}{ Socioeconomic status } \\
\hline High & I & & \\
\hline Middle & 0.82 & $0.59-1.16$ & 0.268 \\
\hline Low & 1.67 & $1.04-2.67$ & 0.033 \\
\hline \multicolumn{4}{|c|}{ Academic achievement } \\
\hline Average & I & & \\
\hline Above average & 1.49 & $0.99-2.25$ & 0.054 \\
\hline Below average & 1.77 & $1.25-2.50$ & $<0.00 \mathrm{I}$ \\
\hline \multicolumn{4}{|c|}{ Depressive symptoms } \\
\hline No & 1 & & \\
\hline Yes & 1.88 & I.38-2.55 & $<0.001$ \\
\hline \multicolumn{4}{|c|}{ Body image satisfaction } \\
\hline High & 1 & & \\
\hline Average & 0.97 & $0.64-1.46$ & 0.861 \\
\hline Low & 1.10 & $0.72-1.68$ & 0.671 \\
\hline \multicolumn{4}{|c|}{ Perceived health status } \\
\hline Good & I & & \\
\hline Fair & 1.02 & $0.74-1.40$ & 0.906 \\
\hline Poor & 1.46 & $0.96-2.22$ & 0.078 \\
\hline \multicolumn{4}{|c|}{ Perceived poor relationship with parents } \\
\hline No & 1 & & \\
\hline Yes & 1.46 & $1.00-2.14$ & 0.049 \\
\hline
\end{tabular}

as younger children might experience bullying by older children. The second major explanation is that younger children have not yet acquired the social skills to effectively deal with bullying incidents. Furthermore, the reduction in bullying victimization by age could be attributable to agerelated changes as youth socially adapt as they age. ${ }^{12}$ It could also reflect equalization in physical size and, consequently, increased effectiveness at inhibiting bullying; alternatively, it might reflect differences in the circumstances of elementary, middle, and high school students with respect to social climate and academic demands. ${ }^{12}$

Similar to other studies, our results have found that girls report being victimized by bullying more often than boys. ${ }^{10,12}$ This might be because boys report being victimized less frequently than girls in Korea, where self-reporting rather than peer-reporting methods are used. ${ }^{14}$ On the other hand, some studies have found that boys are more often victimized than girls, although victimization varies by type..$^{20,21}$ Boys are more likely to experience physical victimization, whereas girls are more likely to be targets of indirect bullying. ${ }^{22}$

The present study found that, after adjusting for age and sex, bullying victimization was associated with lower SES, poorer perceived relationship with parents, lower than average academic achievement, and more depressive symptoms.
Parental SES seems to be correlated with bullying victimization. In the present study, low SES was significantly associated with bullying victimization. Previous studies have also suggested that adolescents from families with a lower SES are more often victimized and face more severe longterm mental health consequences compared to victims from wealthier social backgrounds. ${ }^{23}$

The results of our study also indicate that a perceived poor relationship with parents was related to bullying victimization. A warm and positive parent-child relationship is associated with both emotional and behavioral resilience in response to bullying victimization, ${ }^{24}$ and effective socialization might reduce the risk of being bullied or lead to an effective response to victimization. ${ }^{21}$ Furthermore, these findings are consistent with developmental theories that suggest congruence between early caregiving experiences and later peer interactions. ${ }^{25}$ For example, attachment theory suggests that children internalize important aspects of caregiving relationships, which then influence their behavior in later relationships with peers. ${ }^{26}$ Thus, consequent negative representations of self, others, and relationships are thought to transmit both adaptive and maladaptive social patterns across relationships. ${ }^{25}$

Consistent with previous research, the results of our study showed that lower academic achievement was associated with victimization. Research on the link between bullying victimization and academic variables has shown that bullied children were more likely than their non-bullied peers to avoid school and, on average, to have lower achievement. ${ }^{27,28}$ Previous studies support the assertion that bullying impairs the concentration and subsequent academic achievement of victims. ${ }^{29,30}$ In one study from Great Britain, one-third of bullied children reported impaired concentration and feeling nervous or panicked. ${ }^{31}$ In a study of 204 Midwestern American middle and high school students, $90 \%$ of students reported a drop in grades and an increase in anxiety as a result of bullying. ${ }^{32}$

The association we found between bullying victimization and depressive symptoms is consistent with previous studies. ${ }^{14,21,33}$ During adolescent development, when peer relationships are of utmost importance, ${ }^{34}$ events related to such relationships, such as being bullied, can cause trauma severe enough to lead to depression. Increased emotional dysregulation and lowered self-esteem following victimization from bullying may act as mediators between being bullied and psychiatric symptoms, such as depression. ${ }^{35,36}$ On the other hand, depressed adolescents with negative self-perceptions might expect that others will behave in a rejecting or hostile 
way and perceive this to be the case in social interactions that are meant by others to be neutral or even positive. ${ }^{37,38}$ Finally, it is also possible that the development of social skills and the ability to defend oneself are impaired among depressed adolescents, who therefore become easy targets for bullies. ${ }^{33}$

In the present study, body dissatisfaction was not associated with bullying victimization. Contrary to our result, some studies have found an association between body dissatisfaction and bullying victimization. ${ }^{39,40}$ There was only one study in Korea which related bullying victimization to poor body satisfaction among primary school students. ${ }^{14}$ Further research is needed to investigate an association between body dissatisfaction and bullying victimization among all age groups of adolescents in Korea.

Our population-based study assessed the prevalence of bullying victimization among adolescents. One important strength of the present study is that it involved a large sample of Jeju adolescents that included all age groups. The results of this study also enable a better understanding of the patterns of bullying victimization in the different circumstances of elementary, middle and high school and identify factors related to bullying victimization.

The present study found that adolescents from families with a lower socioeconomic status have a particularly high risk of being involved in bullying, especially as victims. It might be worthwhile to teach children with a lower socioeconomic status certain social skills and strategies to cope with bullying situations. Symptoms of depression are associated with an increased risk of suicide, and students who were victimized have significantly higher risks of suicidal ideation and suicidal behaviors. ${ }^{5}$ Mental health professionals should evaluate symptoms of depression and suicidal behaviors in bullying victims. Parents should also be aware of problems and be encouraged to support victimized adolescents.

Results from the present study suggest that the experience of bullying victimization can have adverse effects on a substantial number of students and highlight the importance of disrupting the repeated pattern of victimization. Therefore, our findings should be considered in the development of early prevention or intervention programs for school bullying to target susceptible groups of adolescents.

\section{Limitations}

The present study had several limitations. First, all items on this school-based self-administered survey were subject to recall bias and imprecise reporting. Being a victim could be seen as socially undesirable by adolescents, and this might lead to under-reporting of victimization. Additionally, we did not use standardized assessment tools to identify bullying victimization. Furthermore, no distinction was made between the frequencies of different types of bullying. Although having a peer group is an important protective factor for bullying, it was not addressed in this study. The opportunity to respond to each form of bullying and to specify its frequency of occurrence would be enhanced in future research by using structured assessments. Second, as the study was cross-sectional in nature, the results do not imply causal relationships between bullying behaviors and the other studied parameters. Future studies with a longitudinal study design are needed to assess the potential causal pathways between bullying victimization and other factors. Third, the study might be limited by selection bias. Those adolescents who did poorly in school or who had negative attitudes toward school might have been less likely to have taken part in this schoolbased survey. Fourth, only students attending school were included in this study, and we did not include out-of-school adolescents whose prevalence of high-risk behaviors might be higher than that of school-attending adolescents. Finally, the participants, including the target schools and school grades, were based on a convenience sampling method. Thus, the subjects in this study are not representative of the wider population of students in South Korea.

\section{Acknowledgment}

This study was supported by a research grant (2014-0762) from Jeju National University in 2014.

\section{Disclosure}

The authors report no conflicts of interest in this work.

\section{References}

1. Glew GM, Fan MY, Katon W, Rivara FP, Kernic MA. Bullying, psychosocial adjustment, and academic performance in elementary school. Arch Pediatr Adolesc Med. 2005;159(11):1026-1031.

2. Fekkes M, Pijpers FI, Verloove-Vanhorick SP. Bullying: who does what, when and where? Involvement of children, teachers and parents in bullying behavior. Health Educ Res. 2005;20(1):81-91.

3. Kim YS, Koh YJ, Leventhal BL. Prevalence of school bullying in Korean middle school students. Arch Pediatr Adolesc Med. 2004;158(8): 737-741.

4. Hazemba A, Siziya S, Muula AS, Rudatsikira E. Prevalence and correlates of being bullied among in-school adolescents in Beijing: results from the 2003 Beijing Global School-Based Health Survey. Ann Gen Psychiatry. 2008;7:6.

5. Kim YS, Koh YJ, Leventhal B. School bullying and suicidal risk in Korean middle school students. Pediatrics. 2005;115(2):357-363.

6. Brown DW, Riley L, Butchart A, Kann L. Bullying among youth from eight African countries and associations with adverse health behaviors. Ped Health. 2008;2(3):289-299.

7. Han JS. Bullying and Educational Collapse in Korea. Seoul: Jipmoondang; 2002. 
8. Salmon G, James A, Smith DM. Bullying in schools: self reported anxiety, depression, and self esteem in secondary school children. BMJ (Clinical research ed). 1998;317(7163):924-925.

9. Ando M, Asakura T, Simons-Morton B. Psychosocial influences on physical, verbal, and indirect bullying among Japanese early adolescents. J Early Adolesc. 2005;25(3):268-297.

10. Arslan S, Savaser S, Yazgan Y. Prevalence of peer bullying in high school students in Turkey and the roles of socio-cultural and demographic factors in the bullying cycle. Indian Journal of Pediatrics. 2011;78(8):987-992.

11. Meltzer H, Vostanis P, Ford T, Bebbington P, Dennis MS. Victims of bullying in childhood and suicide attempts in adulthood. Eur Psychiatry. 2011;26(8):498-503.

12. Craig W, Harel-Fisch Y, Fogel-Grinvald H, et al. A cross-national profile of bullying and victimization among adolescents in 40 countries. Int J Public Health. 2009;54(Suppl 2):216-224.

13. Boel-Studt S, Renner LM. Child and family-level correlates of direct and indirect peer victimization among children ages 6-9. Child Abuse Negl. 2014;38(6):1051-1060.

14. Yang SJ, Kim JM, Kim SW, Shin IS, Yoon JS. Bullying and victimization behaviors in boys and girls at South Korean primary schools. J Am Acad Child Adolesc Psychiatry. 2006;45(1):69-77.

15. Kwon SJ, Park TW, Park SH, Yang JC, Chung YC, Chung SK. Prevalence of school bullying and related psychopathology in children and adolescents. J Korean Acad Child Adolesc Psychiatry. 2012;23(3):143-153.

16. Kovacs M. The Children's Depression, Inventory (CDI). Psychopharmacol Bull. 1984;21(4):995-998.

17. Cho S, Lee Y. Development of the Korean form of the Kovacs' Children's Depression Inventory. J Korean Neuropsychiatr Assoc. 1990;29(4): 943-956.

18. Nansel TR, Craig W, Overpeck MD, Saluja G, Ruan WJ. Cross-national consistency in the relationship between bullying behaviors and psychosocial adjustment. Arch Pediat Adolesc Med. 2004;158(8):730-736.

19. Smith PK, Madsen KC, Moody JC. What causes the age decline in reports of being bullied at school? Towards a developmental analysis of risks of being bullied. Educ Res. 1999;41(3):267-285.

20. Pengpid S, Peltzer K. Bullying and its associated factors among school-aged adolescents in Thailand. TheScientificWorldJournal. 2013;2013:254083.

21. Karlsson E, Stickley A, Lindblad F, Schwab-Stone M, Ruchkin V. Risk and protective factors for peer victimization: a 1-year follow-up study of urban American students. Eur Child Adolesc Psychiatry. 2014; 23(9):773-781.

22. Klomek AB, Marrocco F, Kleinman M, Schonfeld IS, Gould MS. Peer victimization, depression, and suicidiality in adolescents. Suicide Life Threat Behav. 2008;38(2):166-180.

23. Jansen DE, Veenstra R, Ormel J, Verhulst FC, Reijneveld SA. Early risk factors for being a bully, victim, or bully/victim in late elementary and early secondary education. The longitudinal TRAILS study. BMC Public Health. 2011;11:440.
24. Arseneault L, Bowes L, Shakoor S. Bullying victimization in youths and mental health problems: "much ado about nothing"? Psychol Med. 2010;40(5):717-729.

25. Shields A, Cicchetti D. Parental maltreatment and emotion dysregulation as risk factors for bullying and victimization in middle childhood. J Clin Child Psychol. 2001;30(3):349-363.

26. Zeanah $\mathrm{CH}$, Zeanah PD. Intergenerational transmission of maltreatment: insights from attachment theory and research. Psychiatry. 1989; 52(2):177-196.

27. Juvonen J, Wang Y, Espinoza G. Bullying experiences and compromised academic performance across middle school grades. J Early Adoles. 2011;31:152-173.

28. Wang W, Vaillancourt T, Brittain HL, et al. School climate, peer victimization, and academic achievement: results from a multi-informant study. Sch Psychol Q. 2014;29(3):360-377.

29. Nansel TR, Overpeck M, Pilla RS, Ruan WJ, Simons-Morton B, Scheidt P. Bullying behaviors among US youth: prevalence and association with psychosocial adjustment. JAMA. 2001;285(16): 2094-2100.

30. Schwartz D, Gorman AH. Community violence exposure and children's academic functioning. J Educ Psychol. 2003;95(1):163-173.

31. Sharp S. How much does bullying hurt? The effects of bullying on the personal wellbeing and educational progress of secondary aged students. Educ Child Psychol. 1995;12(2):81-88.

32. Hazler RJ, Hoover J, Oliver R. What kids say about bullying. Exec Educ. 1992;14(11):20-22.

33. Kaltiala-Heino R, Fröjd S. Correlation between bullying and clinical depression in adolescent patients. Adolesc Health Med Ther. 2011;2: $37-44$.

34. Larson R, Richards MH. Daily companionship in late childhood and early adolescence: changing developmental contexts. Child Dev. 1991; 62(2):284-300.

35. McLaughlin KA, Hatzenbuehler ML, Hilt LM. Emotion dysregulation as a mechanism linking peer victimization to internalizing symptoms in adolescents. J Consult Clin Psychol. 2009;77(5):894-904.

36. Turner HA, Finkelhor D, Ormrod R. The effects of adolescent victimization on self-concept and depressive symptoms. Child Maltreat. 2010;15(1):76-90.

37. Crick NR, Dodge KA. A review and reformulation of social informationprocessing mechanisms in children's social adjustment. Psychol Bull. 1994;115(1):74-101.

38. Prinstein MJ, Cheah CS, Guyer AE. Peer victimization, cue interpretation, and internalizing symptoms: preliminary concurrent and longitudinal findings for children and adolescents. J Clin Child Adolesc Psychol. 2005;34(1):11-24.

39. Lunde C, Frisen A, Hwang CP. Is peer victimization related to body esteem in 10-year-old girls and boys? Body Image. 2006;3(1):25-33.

40. Wilson ML, Viswanathan B, Rousson V, Bovet P. Weight status, body image and bullying among adolescents in the Seychelles. Int J Environ Res Public Health. 2013;10(5):1763-1774.
Neuropsychiatric Disease and Treatment

\section{Publish your work in this journal}

Neuropsychiatric Disease and Treatment is an international, peerreviewed journal of clinical therapeutics and pharmacology focusing on concise rapid reporting of clinical or pre-clinical studies on a range of neuropsychiatric and neurological disorders. This journa is indexed on PubMed Central, the 'PsycINFO' database and CAS,

\section{Dovepress}

and is the official journal of The International Neuropsychiatric Association (INA). The manuscript management system is completely online and includes a very quick and fair peer-review system, which is all easy to use. Visit http://www.dovepress.com/testimonials.php to read real quotes from published authors. 